\title{
Antidepressant therapy with milnacipran and venlafaxine
}

This article was published in the following Dove Press journal:

Neuropsychiatric Disease and Treatment

24 August 2010

Number of times this article has been viewed

\section{Lucilla Mansuy \\ Pierre Fabre Médicament, Toulouse, France}

Correspondence: Lucilla Mansuy

Pierre Fabre Médicament, 31319

Labège Cedex, France

$\mathrm{Tel}+330149108117$

Fax +330149109626

Email lucilla.mansuy@pierre-fabre.com
Abstract: Specific serotonin norepinephrine reuptake inhibitors (SNRIs) have been described as "better tolerated tricyclic antidepressants" or as "boosted" selective serotonin reuptake inhibitors (SSRIs). Venlafaxine has become a therapeutic reference treatment for major depression. Although less widely studied, indirect comparisons with another SNRI, milnacipran, suggest an equivalent efficacy. This paper discusses these indirect comparisons and the recently published first double-blind, head-to-head comparison. Venlafaxine has potency at serotonin transporters which is about 30 -fold greater than that at norepinephrine transporters while milnacipran has a similar potency at each transporter. Thus, at low doses, venlafaxine acts essentially as a SSRI, with significant noradrenergic activity only occurring at higher doses. To overcome the problem of the differing profile of venlafaxine at increasing doses, the first head-to-head study compared the therapeutic effects and tolerability of the two antidepressants when flexibly titrated to the high dose of $200 \mathrm{mg} /$ day. The study showed that the two SNRIs have similar efficacy and safety profiles. Both drugs produced about $42 \%$ remissions at the end of the 20 -week study. The most frequent adverse events in both groups were nausea, dizziness, headache, and sweating. Certain specific differences in tolerability are discussed.

Keywords: milnacipran, venlafaxine, antidepressant efficacy, tolerability, dose-titration

\section{Introduction}

Major depression is a common psychiatric condition with a prevalence of $5 \%-13 \%$ in the general population. ${ }^{1}$ Despite its prevalence and its consequences for both individuals and society in general, depression is only correctly diagnosed in $50 \%$ of cases, and less than $10 \%$ of patients with depression receive appropriate antidepressant treatment of adequate dose and duration. ${ }^{2}$ It is now generally accepted that the minimum duration of antidepressant treatment in order to prevent relapse of the current episode is 6 months. Few randomized, double-blind, clinical studies of antidepressants, however, extend for this length of time.

Most antidepressants act to increase the synaptic concentration of serotonin (5-hydroxytryptamine, 5-HT) and/or norepinephrine (NE), generally by inhibiting the reuptake of one or both of these neurotransmitters. Serotonin and norepinephrine reuptake inhibitors (SNRIs) combine the efficacy of the tricyclic antidepressants (TCAs) with the tolerability of the selective serotonin reuptake inhibitors (SSRIs). ${ }^{3}$ Milnacipran $\left(\right.$ Ixel $\left.^{\circledR}\right)$ and venlafaxine $\left(\right.$ Effexor $\left.^{\circledR}\right)$ are both SNRIs, although they differ in their selectivity inhibition of NE and 5-HT reuptake. Milnacipran has the most balanced ratio of potency for reuptake inhibition of the two neurotransmitters (5HT:NE 1:1.16). ${ }^{4}$ One study has shown milnacipran to inhibit NE reuptake with greater potency than 
5-HT (2.22:1). ${ }^{5}$ Venlafaxine has a 30-fold greater potency for 5 -HT. ${ }^{4}$

TCAs remain the "gold standard" for antidepressant efficacy, although their poor tolerability complicates their use at fully effective doses. ${ }^{6}$ Milnacipran has an efficacy comparable with that of the TCAs ${ }^{7}$ including clomipramine. ${ }^{8}$ A post hoc analysis has shown that milnacipran has greater efficacy than SSRIs in more severely depressed patients. ${ }^{9}$ A global analysis of all dual-acting antidepressants concluded that three antidepressants, ie, milnacipran, duloxetine, and mirtazapine, had "probable superior efficacy" compared with the SSRIs. ${ }^{10}$

Venlafaxine is a widely used antidepressant and has recently been described as a reference treatment for major depression. ${ }^{11}$ In a global analysis of all antidepressants mentioned above, venlafaxine was classified, along with clomipramine, as having "definite superior efficacy". ${ }^{10}$ Juxtaposition of studies or meta-analyses comparing milnacipran with SSRIs and venlafaxine with SSRIs, ${ }^{3}$ suggests that the two SNRIs had similar overall efficacy. A recent meta-analysis of studies comparing newer dual-action antidepressants with SSRIs ${ }^{12}$ concluded a superior efficacy for all the dual-action antidepressants, including milnacipran and venlafaxine (as well as duloxetine, mirtazapine, mianserin, and moclobemide). Again the two antidepressants showed comparable efficacy across all measures.

With the exception of the study described below, there have been no direct comparisons between milnacipran and venlafaxine. One difficulty of directly comparing these two SNRIs is the choice of dose. In the FDA labeling for Effexor the recommended starting dose for venlafaxine is $75 \mathrm{mg} /$ day, which may be increased to $150 \mathrm{mg} /$ day. If needed, the dose may be further increased up to $225 \mathrm{mg} /$ day. In outpatient settings there is no evidence of usefulness of doses greater than $225 \mathrm{mg}$ /day for moderately depressed patients, but more severely depressed inpatients responded to a mean dose of $350 \mathrm{mg}$ /day. Certain patients, including more severely depressed patients, may respond better to higher doses, up to a maximum of $375 \mathrm{mg} /$ day. Because venlafaxine has a 30 -fold selectivity for the reuptake of serotonin, at $75 \mathrm{mg}$ /day it does not significantly modify noradrenergic neurotransmission and acts essentially as a SSRI. ${ }^{13}$ A clinically meaningful effect on noradrenergic neurotransmission is estimated to occur from about $150-200 \mathrm{mg} /$ day. ${ }^{13}$ The adverse effects of venlafaxine have been shown to be dose-dependent. ${ }^{14}$ Thus, depending on the dose chosen for the comparison, venlafaxine can be either a relatively well tolerated SSRI or a less well tolerated SNRI.
Milnacipran has a similar effect on both serotonin and norepinephrine reuptake and thus acts as an SNRI at all doses. ${ }^{3}$ The recommended dose of milnacipran in major depression is $100 \mathrm{mg}$ /day, although various studies carried out with doses 150-300 mg/day have suggested that some patients may benefit from higher doses..$^{15-17}$ These studies have shown that these higher doses of milnacipran are well tolerated by most patients. No new adverse effects are seen at higher doses.

\section{Milnacipran and venlafaxine IR flexibly titrated to $200 \mathrm{mg} /$ day}

The first direct comparison of milnacipran and venlafaxine IR (immediate-release) ${ }^{18}$ was carried out at doses flexibly titrated up to a maximum of $200 \mathrm{mg} /$ day for each compound. In addition, because in clinical practice a major objective is to achieve a long-lasting remission from depression, the study was carried out over a duration of 24 weeks. The choice of the IR formulation of venlafaxine rather than the XR (extendedrelease) formulation was probably chosen to enable identical twice-daily dosing, although this is not mentioned in the publication. ${ }^{18}$

The recommended dose of milnacipran in major depression is $100 \mathrm{mg}$ /day, but studies carried out at doses of 150-300 mg/day suggest that some patients may benefit from higher doses ${ }^{18}$ and milnacipran is frequently used at these doses. The recommended dose range for venlafaxine in outpatients is $75-225 \mathrm{mg}$ /day. Thus, the objective of this study was to explore the efficacy and long-term safety/ tolerability of milnacipran and venlafaxine administered in an outpatient setting at doses of up to $200 \mathrm{mg}$ /day in patients suffering from a major depressive episode.

This multicenter, randomized, double-blind study was carried out in 195 adult outpatients presenting with an episode of recurrent, unipolar, moderate-to-severe (Montgomery-Asberg Depression Rating Scale [MADRS] ${ }^{19}$ score $\geq 23$ ) major depressive disorder. During the first 4 weeks of the study, the dose of each antidepressant was uptitrated (days 1-3, $25 \mathrm{mg}$ /day; days 4-6, $50 \mathrm{mg}$ /day; days 7-13, $100 \mathrm{mg} /$ day; days $14-28,150 \mathrm{mg} /$ day). At day 28 , at the clinician's discretion, the dose was maintained at $150 \mathrm{mg} / \mathrm{day}$, reduced to $100 \mathrm{mg} /$ day, or increased to $200 \mathrm{mg}$ /day. At the end of the 24-week study, the dose was downtitrated by $50 \mathrm{mg} /$ day every 5 days. The daily doses were administered in two identical doses morning and evening, except the initial dose of $25 \mathrm{mg} /$ day (one morning dose only) and the dose of $150 \mathrm{mg} /$ day (50 mg morning and $100 \mathrm{mg}$ evening). Depressive symptoms were assessed weekly using the MADRS. 
Of the 195 patients randomized (milnacipran 97, venlafaxine 98), 134 completed 24 weeks of treatment (milnacipran 60, venlafaxine 74). In both groups, the main reason for premature withdrawal was adverse events (AEs, $51 \%$ on milnacipran, $42 \%$ on venlafaxine). The other reasons for premature withdrawal, such as lack of efficacy or patient decision after recovery, were not stated, so it is not possible to analyze the dropout data in detail.

The baseline characteristics of the patients (Table 1) were similar in both groups, except that there were significantly more patients with a severe depressive episode in the milnacipran group $(63.3 \%$ versus $54 \%$ in the venlafaxine group). Most patients ( $87 \%$ ) had had previous depressive episodes which had been treated with antidepressants. The mean baseline MADRS score of 31.0 in the overall population indicated moderate to severe intensity of the depression.

At the end of the titration period, approximately $90 \%$ of patients were taking an antidepressant dose of either 150 or $200 \mathrm{mg} /$ day (Table 2). This percentage remained constant for both antidepressants through to the end of the study.

The MADRS score decreased progressively throughout the study and was comparable in the two treatment groups (Figure 1). The rate of response ( $\geq 50 \%$ reduction in initial MADRS score) and remission (a MADRS score $\leq 10$, Figure 2) was not clinically or statistically different between the two treatment groups at week 8 or week 24 . Rates of response and remission were also similar with both antidepressants in a subgroup of patients with a severe depressive episode ( $n=104$, Table 3 ) and in patients with a measurable suicide risk ("low" or "moderate" according to the

Table I Demographic characteristics at baseline

\begin{tabular}{|c|c|c|}
\hline & $\begin{array}{l}\text { Milnacipran } \\
(\mathrm{n}=90)\end{array}$ & $\begin{array}{l}\text { Venlafaxine } \\
(\mathrm{n}=\mathbf{8 7})\end{array}$ \\
\hline Women (\%) & 61.1 & 60.4 \\
\hline Mean age (years) $\pm S D$ & $44.6 \pm 11.4$ & $42.7 \pm 12.8$ \\
\hline $\begin{array}{l}\text { Mean duration of current episode } \\
\text { (months) } \pm \text { SD }\end{array}$ & $3.6 \pm 2.8$ & $3.2 \pm 2.2$ \\
\hline $\begin{array}{l}\text { Patients with severe depressive } \\
\text { episode (\%)* }\end{array}$ & 63.3 & 54.0 \\
\hline \multicolumn{3}{|l|}{ Severity of suicide risk** } \\
\hline Low (\%) & 37.8 & 36.3 \\
\hline Moderate (\%) & 4.4 & 4.4 \\
\hline High (\%) & I.I & 0 \\
\hline MADRS (mean $\pm S D)$ & $31.4 \pm 4.6$ & $30.7 \pm 4.4$ \\
\hline CGI-S (mean $\pm S D)$ & $5.1 \pm 0.7$ & $5.2 \pm 0.7$ \\
\hline
\end{tabular}

Notes: *Severe depressive episode as defined by DSM-IV; **Moderate or mild suicide risk determined using the MINI.

Abbreviations: CGI-S, clinical global impressions scale; MADRS, MontgomeryAsberg depression rating scale; MINI, mini international neuropsychiatric interview; $\mathrm{SD}$, standard deviation.
Mini International Neuropsychiatric Interview) at baseline ( $\mathrm{n}=75$, Table 3$)$.

In the vast majority of cases, the therapeutic benefit achieved at week 8 was maintained over the long term. Overall, $93 \%$ of responders at week 8 were also responders at week 24 (milnacipran, 95\%, venlafaxine 87\%), while $89.3 \%$ of the patients in remission at week 8 were also in remission at week 24 (milnacipran 87\%, venlafaxine 92\%).

During treatment, AEs were reported by $72 \%$ patients in the milnacipran group and $74 \%$ patients in the venlafaxine group. In both groups, the most common treatment-emergent AEs (occurring in $\geq 10 \%$ of patients) were nausea, headache, dizziness, constipation, hyperhidrosis, palpitations, and dry mouth (Figure 3). After the end of treatment during the downtitration, the incidence of AEs was greater in the venlafaxine group (14\% versus $7 \%$ in the milnacipran group). In males, dysuria was experienced only in the milnacipran group $(20 \%)$, while orgasmic disorders were only reported in the venlafaxine group (17\%). Most of the AEs occurred during the first 3 weeks of treatment, and $85 \%$ of them were of mild or moderate severity. Five patients in the milnacipran group and seven patients in the venlafaxine group experienced at least one serious AE. Only three serious AEs (all in the venlafaxine group) were considered to be possibly related to the study treatment (one worsening depression, one anxiety related to an overdose of venlafaxine, and one biliary colic).

Dysuria during treatment with milnacipran has been reported previously. ${ }^{7,20}$ It is probably a consequence of increased noradrenergic tone of the urethral sphincter. ${ }^{21}$ This is consistent with the fact that the dysuria induced by milnacipran can be reversed by administration of a urinary tract-specific alpha ${ }_{1}$ antagonist, such as tamsulosin and alfuzosin. ${ }^{22}$ Dysuria is also experienced with other antidepressants having a major impact on the noradrenergic system, such as reboxetine. ${ }^{23}$

Orgasmic disorder was spontaneously reported in $17 \%$ of patients treated with venlafaxine but in no patients treated with milnacipran. The absence of sexual dysfunction with milnacipran is consistent with other studies ${ }^{24,25}$ which

Table 2 Doses of antidepressants received by patients at the end of the titration period

\begin{tabular}{lll}
\hline & Patients (\%) & \\
\cline { 2 - 3 } & Milnacipran & Venlafaxine \\
\hline $150-200 \mathrm{mg} /$ day & 88.6 & 90.1 \\
$150 \mathrm{mg} /$ day & 30.4 & 43.8 \\
$200 \mathrm{mg} /$ day & 58.2 & 46.3 \\
\hline
\end{tabular}

At the end of treatment, the distribution of doses did not differ significantly from that at the end of the titration period in the two groups. 


\section{Days of treatment}

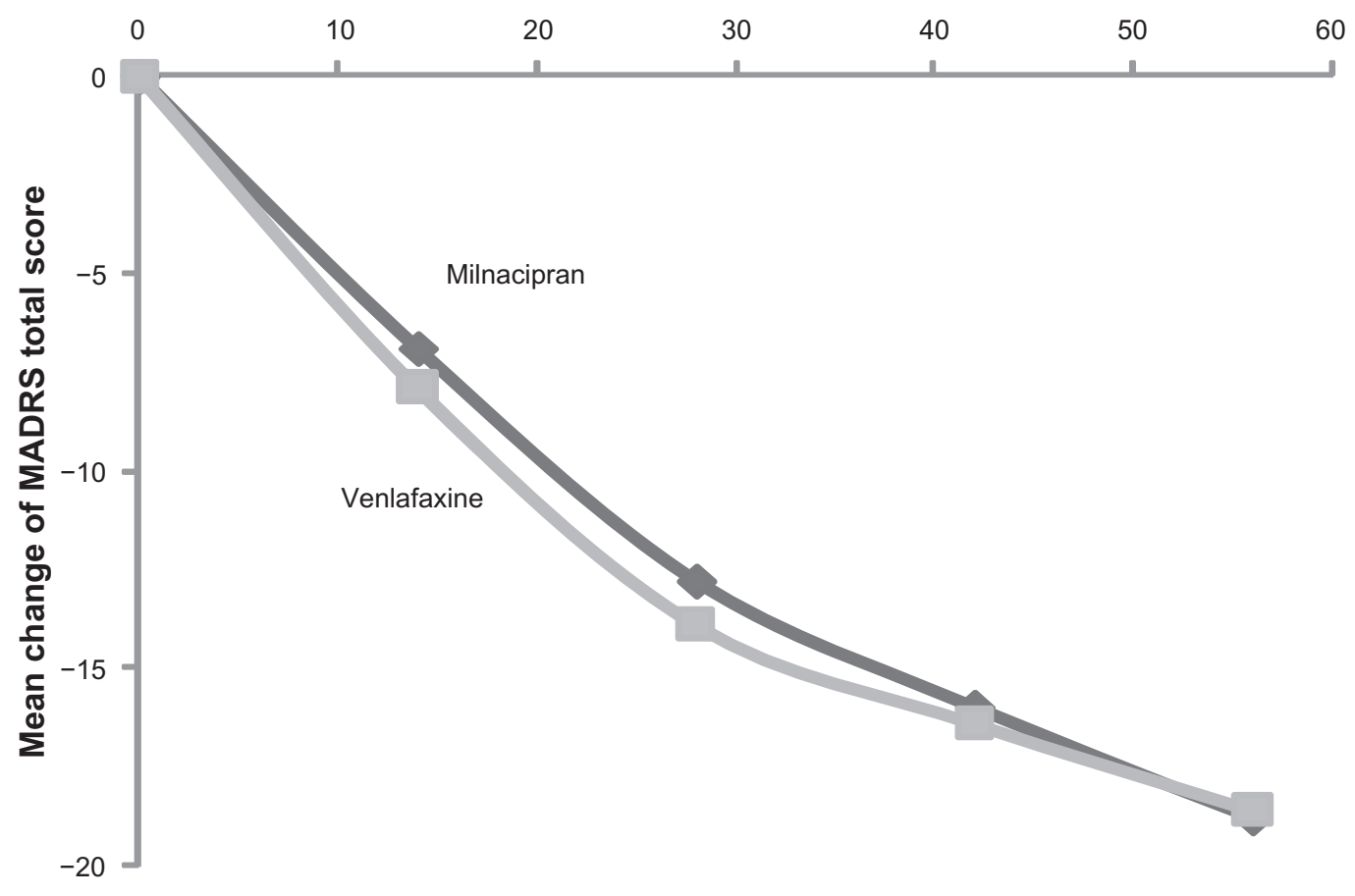

Figure I MADRS total score (mean changes from baseline) over the first 8 weeks of treatment Notes: The values are mean \pm SEM of the observed case population $(n=60$ milnacipran; $n=74$ venlafaxine).

have shown that milnacipran does not cause treatmentemergent sexual dysfunction. Antidepressant-induced sexual dysfunction is generally thought to result from stimulation of 5-HT 2 receptors, ${ }^{26}$ although this is probably not the only mechanism. The absence of these effects with milnacipran, which also stimulates serotonergic transmission but does not act as an antagonist at 5- $\mathrm{HT}_{2}$ receptors, suggests that sexual dysfunction induced via stimulation of postsynaptic $5-\mathrm{HT}_{2}$ receptors may be attenuated or completely blocked by simultaneous noradrenergic stimulation, although the mechanism of this effect remains to be elucidated.

The study discussed in this review shows that milnacipran and venlafaxine, when administered at flexible doses of up to $200 \mathrm{mg} /$ day, have similar efficacy and safety profiles. There are, however, certain differences between the two SNRIs that were not explored in this study. Whereas milnacipran has no effect on any cytochrome (CYP) P450 enzyme, ${ }^{27}$ venlafaxine is a substrate for CYP2D6 which is responsible for its transformation into the active metabolite, desvenlafaxine. ${ }^{28}$ There is considerable polymorphism of CYP2D6, with nearly $10 \%$ of "slow metabolizers" in the Caucasian population. ${ }^{29}$ This property is likely to induce unexpected variation in therapeutic effect and tolerability. ${ }^{28}$ In addition, as stated in the FDA labeling, venlafaxine's tolerability can be influenced by coadministration of drugs that inhibit CYP2D6, such as cimetidine and certain antipsychotics. ${ }^{30} \mathrm{~A}$ recent study has shown that venlafaxine intoxication frequently (in $46 \%$ of cases) occurs in the presence of drugs interacting at the

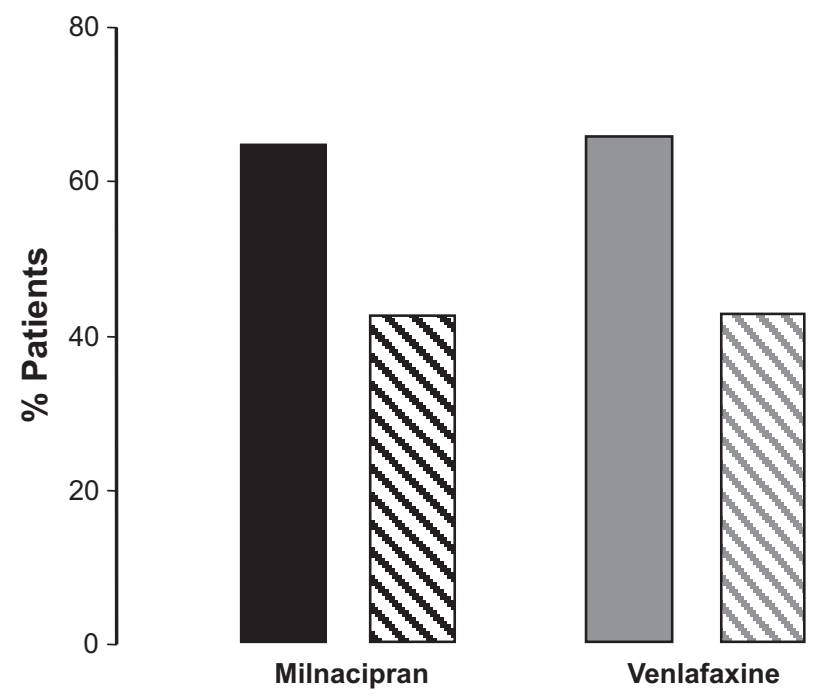

Figure 2 Responders and remissions (MADRS) after 8 weeks Key: filled columns $=$ responders ( $\geq 50 \%$ reduction in initial MADRS score); hatched columns $=$ remissions $($ MADRS score $\leq 10)$.

Notes: Values are based on the whole randomized population using the last observer carried forward method population ( $n=97$ milnacipran; $n=98$ venlafaxine). 
Table 3 Rates of response and remission

\begin{tabular}{|c|c|c|c|c|}
\hline & \multicolumn{2}{|c|}{ Responders (\%) } & \multicolumn{2}{|c|}{ Remissions (\%) } \\
\hline & Week 8 & Week 24 & Week 8 & Week 24 \\
\hline \multicolumn{5}{|c|}{ Patients with a severe depressive episode* at inclusion } \\
\hline Milnacipran & 61.4 & 71.9 & 29.8 & 49.1 \\
\hline Venlafaxine & 61.7 & 74.5 & 31.9 & 53.2 \\
\hline \multicolumn{5}{|c|}{ Patients with measurable suicide risk** at inclusion } \\
\hline Milnacipran & 65.8 & 71.1 & 44.7 & 52.6 \\
\hline Venlafaxine & 59.5 & 64.9 & 35.1 & 54.1 \\
\hline
\end{tabular}

Notes: *Severe depressive episode as defined by DSM-IV; **mild or moderate suicide risk determined using the MINI.

CYP P450 2DC isoenzyme, resulting in higher venlafaxine concentrations. ${ }^{31}$

Finally, the two antidepressants vary considerably in terms of safety in overdose. Milnacipran has been shown to be safe in overdose, with doses as high as $2.8 \mathrm{~g}$ causing no serious effects and no mortality. ${ }^{32}$ No deaths have been reported following milnacipran overdose, with the exception of a case of multiple drug overdose where high blood levels of milnacipran, fluoxetine, norfluoxetine, sertraline, cyamemazine, nordiazepam, and oxazepam were found..$^{33}$ In contrast, lethal consequences of venlafaxine overdose have been reported, with a frequency of over 34 per 1000 person-years. This was significantly greater than other antidepressants, including the TCAs. ${ }^{34} \mathrm{~A}$ study carried out in the UK showed that the fatal toxicity index (deaths/million prescriptions) of venlafaxine (13) was similar to that of TCAs such as amitriptyline (15). ${ }^{35}$ Another more recent fatal toxicity survey, however, showed greater toxicity for TCAs (13.8) than for venlafaxine (2.5), although the latter was considerably more toxic than the SSRIs (0.5). ${ }^{36}$ A prominent feature of cases of venlafaxine intoxication is the frequent presence (in $46 \%$ of cases) of drugs interacting at the CYP P450, resulting in higher venlafaxine concentrations. ${ }^{36}$

\section{Conclusion}

Indirect comparisons $\mathrm{s}^{3,12}$ and everyday clinical experience has suggested that milnacipran and venlafaxine have similar efficacy. The first head-to-head comparison at a dose of $200 \mathrm{mg} / \mathrm{day}^{18}$ has confirmed this suggestion. The study also showed that concerns about tolerability at higher doses were unfounded. When the SNRIs were titrated flexibly over a period of 4 weeks, both milnacipran and venlafaxine were relatively well tolerated, with about $90 \%$ of patients achieving doses of 150 or $200 \mathrm{mg} /$ day.

Venlafaxine has become a therapeutic reference for major depression. ${ }^{11}$ Although less widely studied, indirect comparisons and the head-to-head study discussed here show

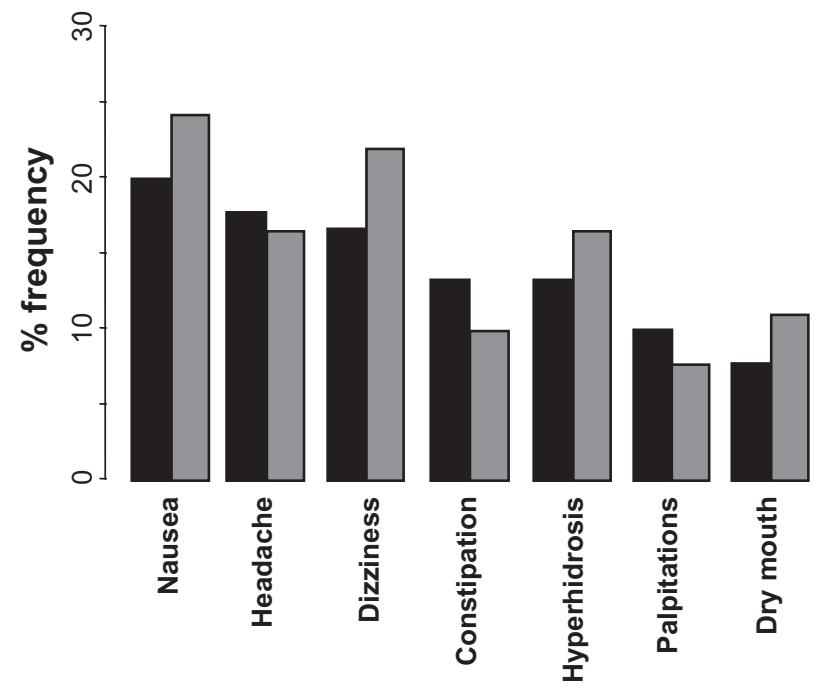

Figure 3 Principal adverse events experienced with milnacipran and venlafaxine during the study.

Key: black columns = milnacipran; grey columns = venlafaxine .

Notes: Only adverse events with a frequency $\geq 10 \%$ are shown.

that milnacipran can be considered to be clinically equivalent to venlafaxine in terms of efficacy, with certain advantages when sexual dysfunction, overdose, or polymedication are of concern.

\section{Disclosure}

The author is employed by Pierre Fabre Médicament manufacturers of milnacipran.

\section{References}

1. O'Connor EA, Whitlock EP, Beil TL, Gaynes BN. Screening for depression in adult patients in primary care settings: A systematic evidence review. Ann Intern Med. 2009;151:793-803.

2. Lépine JP, Gastpar M, Mendlewicz J, et al. Depression in the community: The first pan-European study DEPRES (Depression Research in European Society). Int Clin Psychopharmacol. 1997;1:19-29.

3. Stahl SM, Grady MM, Moret C, Briley M. SNRIs: Their pharmacology, clinical efficacy, and tolerability in comparison with other classes of antidepressants. CNS Spectr. 2005;10:732-747.

4. Koch S, Hemrick-Luecke SK, Thompson LK, et al. Comparison of effects of dual transporter inhibitors on monoamine transporters and extracellular levels in rats. Neuropharmacology. 2003;45(7): 935-944.

5. Vaishnavi SN, Nemeroff CB, Plott SJ, et al. Milnacipran: A comparative analysis of human monoamine uptake and transporter binding affinity. Biol Psychiatry. 2004;55(3):320-322.

6. Peretti S, Judge R, Hindmarch I. Safety and tolerability considerations: Tricyclic antidepressants vs selective serotonin reuptake inhibitors. Acta Psychiatr Scand. 2000;403 Suppl:17-25.

7. Kasper S, Pletan Y, Solles A, Tournoux A. Comparative studies with milnacipran and tricyclic antidepressants in the treatment of patients with major depression: A summary of clinical trial results. Int Clin Psychopharmacol. 1996;11 Suppl 4:35-39.

8. Steen A, Den Boer JA. A double-blind six months comparative study of milnacipran and clomipramine in major depressive disorder. Int Clin Psychopharmacol. 1997;12(5):269-281. 
9. Lopez-Ibor J, Guelfi JD, Pletan Y, et al. Milnacipran and selective serotonin reuptake inhibitors in major depression. Int Clin Psychopharmacol. 1996;11 Suppl 4:41-46.

10. Montgomery SA, Baldwin DS, Blier P, et al. Which antidepressants have demonstrated superior efficacy? A review of the evidence. Int Clin Psychopharmacol. 2007;22(6):323-329.

11. Bauer M, Tharmanathan P, Volz HP, et al. The effect of venlafaxine compared with other antidepressants and placebo in the treatment of major depression: A meta-analysis. Eur Arch Psychiatry Clin Neurosci. 2009;259(3):172-185.

12. Papakostas GI, Thase ME, Fava M, et al. Are antidepressant drugs that combine serotonergic and noradrenergic mechanisms of action more effective than the selective serotonin reuptake inhibitors in treating major depressive disorder? A meta-analysis of studies of newer agents. Biol Psychiatry. 2007;62(11):1217-1227.

13. Debonnel G, Saint-André E, Hébert C, et al. Differential physiological effects of a low dose and high doses of venlafaxine in major depression. Int J Neuropsychopharmacol. 2007;10(1):51-61.

14. Gutierrez MA, Stimmel GL, Aiso JY. Venlafaxine: A 2003 update. Clin Ther. 2003;25(8):2138-2154.

15. Ansseau M, Von Frenckell R, Gérard MA, et al. Interest of a loading dose of milnacipran in endogenous depressive inpatients. Comparison with the standard regimen and with fluvoxamine. Eur Neuropsychopharmacol. 1991;1:113-121.

16. Hayashi M, Mimura M, Otsubo T, et al. Effect of high-dose milnacipran in patients with depression. Neuropsychiatric Dis Treat. 2007;3(5):699-702.

17. Okumura K, Furukawa TA. Remission rates with milnacipran $100 \mathrm{mg} /$ day and $150 \mathrm{mg} /$ day in the long term treatment of major depression. Clin Drug Invest. 2006;26(3):135-142.

18. Olié J-P, Gourion D, Montagne A, et al. Milnacipran and venlafaxine at flexible doses (up to $200 \mathrm{mg} /$ day) in the outpatient treatment of adults with moderate-to-severe major depressive disorder: A 24-week randomized, double-blind exploratory study. Neuropsychiatr Dis Treat. 2010;6:71-79.

19. Montgomery SA, Asberg M. A new depression scale designed to be sensitive to change. Br J Psychiatry. 1979;13:382-389.

20. Spencer CM, Wilde MI. Milnacipran. A review of its use in depression. Drugs. 1998;56(3):405-427.

21. Demyttenaere K, Huygens R, Van Buggenhout R. Tamsulosin as an effective treatment for reboxetine-associated urinary hesitancy. Int Clin Psychopharmacol. 2001;16(6):353-355.
22. Kasper S, Wolf R. Successful treatment of reboxetine-induced urinary hesitancy with tamsulosin. Eur Neuropsychopharmacol. 2002;12(2):119-122.

23. Scates AC, Doraiswamy PM. Reboxetine: A selective norepinephrine reuptake inhibitor for the treatment of depression. Ann Pharmacother. 2000;34(11):1302-1312.

24. Baldwin D, Moreno RA, Briley M. Resolution of sexual dysfunction during acute treatment of major depression with milnacipran. Hum Psychopharmacol. 2008;23(6):527-532.

25. Takahashi H, Ishigooka J. Improvement of selective serotonin reuptake inhibitor-induced sexual dysfunction without worsening of depressive symptom after switching to milnacipran. Clin Neuropharmacol. 2009;32(3):177-178.

26. Baldwin D, Thomas S, Birtwistle J. Effects of antidepressant drugs on sexual function. Int J Psychiatry Clin Pract. 1997;1:47-58.

27. Paris BL, Ogilvie BW, Scheinkoenig JA, et al. In vitro inhibition and induction of human liver cytochrome p450 enzymes by milnacipran. Drug Metab Dispos. 2009;37(10):2045-2054.

28. Shams ME, Arneth B, Hiemke C, et al. CYP2D6 polymorphism and clinical effect of the antidepressant venlafaxine. J Clin Pharm Ther. 2006;31(5):493-502.

29. Alván G, Bechtel P, Iselius L, Gundert-Remy U. Hydroxylation polymorphisms of debrisoquine and mephenytoin in European populations. Eur J Clin Pharmacol. 1990;39(6):533-537.

30. Cupp MJ, Tracy TS. Cytochrome P450: New nomenclature and clinical implications. Am Fam Physician. 1998;57(1):107-116.

31. Launiainen T, Rasanen I, Vuori E, Ojanperä I. Fatal venlafaxine poisonings are associated with a high prevalence of drug interactions. Int J Legal Med. 2010, Apr 30. [Epub ahead of print].

32. Montgomery SA. Tolerability of serotonin norepinephrine reuptake inhibitor antidepressants. CNS Spectr. 2008;13(7 Suppl 11):27-33.

33. Fanton L, Bévalot F, Grait H, et al. Fatal intoxication with milnacipran. J Forensic Leg Med. 2008;15:388-390.

34. Tiihonen J, Lönnqvist J, Wahlbeck K, et al. Antidepressants and the risk of suicide, attempted suicide, and overall mortality in a nationwide cohort. Arch Gen Psychiatry. 2006;63(12):1358-1367.

35. Cheeta S, Schifano F, Oyefeso A, et al. Antidepressant-related deaths antidepressant prescriptions in England and Wales, 1998-2000. Br J Psychiatry. 2004;184:41-47.

36. Hawton K, Bergen H, Simkin S, et al. Toxicity of antidepressants: Rates of suicide relative to prescribing and non-fatal overdose. Br J Psychiatry. 2010;196:354-358.
Neuropsychiatric Disease and Treatment

\section{Publish your work in this journal}

Neuropsychiatric Disease and Treatment is an international, peerreviewed journal of clinical therapeutics and pharmacology focusing on concise rapid reporting of clinical or pre-clinical studies on a range of neuropsychiatric and neurological disorders. This journal is indexed on PubMed Central, the 'PsycINFO' database and CAS, and is the official

\section{Dovepress}

journal of The International Neuropsychiatric Association (INA). The manuscript management system is completely online and includes a very quick and fair peer-review system, which is all easy to use. Visit http://www.dovepress.com/testimonials.php to read real quotes from published authors. 